Volume: 2, Issue: 1, January-March 2017, Pages: 113, DOI: http://dx.doi.org/10.19082/ah113

\title{
RANDOM SURVIVAL FORESTS IN THE PRESENCE OF COMPETING RISKS
}

\author{
Freshteh osmani ${ }^{1}$, Atefeh hajian ${ }^{2}$, Ebrahim hajizadeh ${ }^{3, *}$
}

Department of Biostatistics, Faculty of Medical Sciences, Tarbiat Modares University,Tehran,Iran

Correspondence:

Tel: +98.82883080, E-mail: hajizadeh@modares.ac.ir

\section{TYPE OF ARTICLE: CONFERENCE ABSTRACT}

\begin{abstract}
Introduction: Random forests in medical research are a popular method for creating models to predict event risk. This method requires no assumption, and one of the advantages of this method is election prediction variables in order of importance. This study compares the competing risks forests as a nonparametric method with causespecific Cox as a semi-parametric method, along with specifying risk factors of colorectal cancer.

Methods: This study is a retrospective cohort study. Data were collected from 1000 patients with colorectal cancer in the Taleghani Hospital between the years 1996-2011. By using a cross-validation method, two criteria of the competing risks forests (splitting log-rang and gary) and cause-specific Cox regression models have been fitted to the data. The best model to predict was determined by using concordance index and integrated brier score (IBS) in the study.

Results: A total of 1000 patients $37.9 \%$ women with mean $( \pm$ SD) age of $52.04( \pm 15.534)$ and $62.1 \%$ male with mean $( \pm \mathrm{SD})$ age of $53.41( \pm 16.358)$ participated in this study. The IBS for splitting log-rang, gary, and causespecific Cox regression is $.175, .178$, and .185 , and the values of cross-validation index for the three models are $.714, .711$, and .649 , respectively.

Conclusion: According to the results of this study, the competing risks forest model has better performance in predictability compared with the other two models.

KEYWORDS: Tree-Based models, Random survival forests, Competing risk forest, Colorectal cancer
\end{abstract}

\footnotetext{
Abstracts of First National Congress of Medical Informatics, Mashhad, Iran, February 2017

(C) 2017 The Authors. This is an open access article under the terms of the Creative Commons Attribution-NonCommercialNoDerivs License, which permits use and distribution in any medium, provided the original work is properly cited, the use is non-commercial and no modifications or adaptations are made.
} 